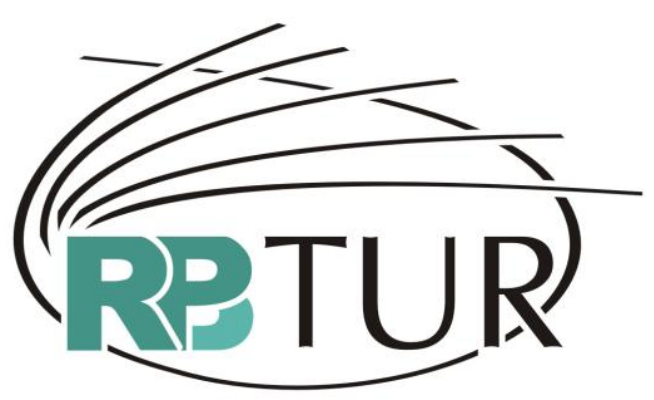

REVISTA BRASILEIRA DE PESQUISA EM TURISMO

\title{
A REGIONALIZAÇÃO TURÍSTICA DO RIO GRANDE DO SUL E SUA CONTRIBUIÇÃO COMO REFERÊNCIA PARA A GESTÃO REGIONALIZADA DO TURISMO NO BRASIL
}

\author{
REGIONALIZATION OF TOURISM IN RIO GRANDE DO SUL \\ AND ITS CONTRIBUTION AS A REFERENCE FOR BRAZILIAN \\ TOURISM MANAGEMENT IN REGIONAL BASIS
}

\section{LA REGIONALIZACIÓN TURÍSTICA EN RIO GRANDE DEL SUR Y SU CONTRIBUCIÓN COMO REFERENCIA PARA LA GESTIÓN REGIONALIZADA DEL TURISMO EN BRASIL}

Alvaro Luiz Machado ${ }^{1}$

Edegar Luis Tomazzoni ${ }^{2}$

Resumo: O objetivo deste artigo é analisar os processos de regionalização turística do estado do Rio Grande do Sul e as características da determinação dos espaços turísticos regionalizados, com base em conceitos de espaço, território, regionalidade e centralidade. Trata-se de pesquisa exploratória e qualitativa, cujo método consiste em revisão histórica, por meio de investigação e de compilação de informações de arquivos da Secretaria de Estado do Turismo do Estado do Rio Grande do Sul, identificando-se as etapas de aplicação de políticas públicas de regionalização, de acordo com programas de diversos governos. Constatou-se que, na regionalização, predominou a decisão política, priorizando as possibilidades de captação de investimentos externos resultados de programas governamentais de desenvolvimento turístico regionalizado. As características de cada região, para organização do turismo, não foram definidas com a participação direta das comunidades locais. Mesmo assim, o Rio Grande do Sul é pioneiro e referência em implementação de modelos de gestão pública regional do turismo no Brasil.

Palavras chave: Turismo. Regionalização. Espaço. Território. Rio Grande do Sul. Brasil.

\footnotetext{
${ }^{1}$ Mestre em Turismo pela Universidade de Caxias do Sul. Docente do Curso de Bacharelado em Turismo das Faculdades Integradas de Taquara (RS). Email: alv_ecotur@hotmail.com

2 Doutor em Ciências da Comunicação com Ênfase em Turismo e Desenvolvimento Regional pela Universidade de São Paulo (USP). Docente do Programa de Pós-Graduação - Mestrado em Turismo da Universidade de Caxias do Sul (UCS). Email: edegarlt@terra.com.br
} 
Abstract: The scope of the article is to analyze tourism regionalization processes in Rio Grande do Sul State (Brazil) and the characteristics leading to determination of regional tourist spaces considering concepts of space, territory, regionalism and centrality. Exploratory and qualitative methodologies were applied. Informations collected at the Official Tourism Department of Rio Grande do Sul State were organized regarding historic periods and showed the steps of public policies in regionalization processes, according to the different governs. The analysis identified that political decisions had priority in the definition of regional territories aiming at external investments. The definition of each region characteristics for regional tourism organization did not have the direct participation of local communities. Nevertheless Rio Grande do Sul State is pioneer and referential in implementing models of regional public management tourism in Brazil.

Keywords: Tourism. Regionalization. Space. Territory. Rio Grande do Sul State. Brazil.

Resumen: El objetivo de este artículo es analizar los procesos de regionalización turística del estado de Rio Grande del Sur (Brasil) y sus características en lo que se refiere a la definición de los espacios turísticos regionalizados, tomando como base los conceptos de espacio, territorio, regionalidad y centralidad. Es una investigación exploratoria y cualitativa apoyada en la revisión histórica y la recopilación de informaciones de archivo de la Secretaria de Estado de Turismo del Estado de Rio Grande del Sur, en los que se identividaron las etapas de aplicación de políticas públicas de regionalización en los diversos programas de gobierno. Se constató que en la regionalización predominaron las decisiones políticas en base a la posibilidad de captación de inversiones externas como resultado de programas gubernamentales de desarrollo turístico regionalizado. Las características de cada región para la organización del turismo no se definieron con la participación directa de las comunidade locales. A pesar de ello, Rio Grande del Sur es pionero y referencia en la implementación de modelos de gestión pública regional del turismo en Brasil.

Palabras clave: Turismo. Regionalización. Espacio. Territorio. Rio Grande del Sur. Brasil.

\section{Introdução}

Uma das características da pós-modernidade é a nova relação espaçotempo, resultado da utilização da tecnologia, para conectar lugares e homens, num mundo sem isolamento territorial, em razão da transposição das fronteiras e da relativização das distâncias. Surgem, assim, novas possibilidades de fluidez e mais facilidade de circulação de pessoas, de produtos e de informações.

Configuram-se processos cosmopolitas paradoxais, pois, ao mesmo tempo em que se padronizam as culturas e se uniformiza a história, estimula- 
se a regionalização, por meio de nova valorização do espaço local, resultante da possibilidade de diferenciação diante de outros lugares. Em tal contexto, é possível identificar elementos que auxiliam na análise da ordenação da atividade turística, identificando a organização regional como um dos mais frequentes critérios de delimitação geográfica ou territorial.

O Estado do Rio Grande do Sul tem desenvolvido variadas propostas de organização regional, firmando bases de pertencimento e de identidades regionais, na elaboração de rotas, de roteiros e de produtos turísticos, valendo-se de políticas públicas, que se identificam com o processo de definição das demandas do turismo.

Ao analisar os processos de definição das regionalidades, como cenários para o desenvolvimento do turismo, tornam-se pertinentes alguns questionamentos quanto à visão do planejamento. O espaço do turismo seria determinado pelas relações econômicas do território, ou serviria como um novo modelo para a determinação de organizações regionais? As regiões turísticas são ordenadas com base em conceitos de paisagem, cultura, espaço geográfico, ou são resultados de programas políticos e administrativos de desenvolvimento local? Que fatores devem ser considerados na definição dos limites de uma região turística?

Feitas estas considerações, é importante entender como se processa a relação de territorialidade com a organização pública do turismo e compreender, sem a pretensão de definir ou de esgotar os diversos conceitos, o entendimento de espaço, de território, de lugar, de zona e de região turística. Na tentativa de enriquecer a compreensão das diferentes formas de espacialização do turismo na sociedade, defini-se o objetivo deste artigo que é analisar os processos de regionalização turística do Rio Grande do Sul e as características da determinação dos espaços turísticos regionalizados do estado.

O método de pesquisa, de natureza qualitativa e exploratória, compreendeu a abordagem conceitual dos espaços e dos atores do turismo, no desempenho de seu papel como aglutinadores no ordenamento da atividade 
turística, com base em revisão bibliográfica. Além disso, o método abrangeu pesquisa de revisão dos programas de regionalização implantados no Estado do Rio Grande do Sul, a partir do ano de 1976, identificando semelhanças e diferenças, nos variados processos de organização turística regional. A razão para a seleção desse período foi a possibilidade de investigação e de análise de documentos elaborados pelo governo do Estado do Rio Grande do Sul relacionados à temática do trabalho.

\section{Espaço, Território, Região e Turismo}

A ideia de espaço representa muito mais que construção de singularidade, podendo ser entendida como um processo de particularidades, em que ocorre a mediação entre o universal, representado pelo processo geral, e o singular. Trata-se de uma nova visão do regional, cujas formas e conteúdos apresentam movimentos acelerados. É, sobretudo no local, que ocorrem condições para a realização de relações globais em uma base territorialista, que procura "afirmar a diferença frente à homogeneização imposta pelo processo de desenvolvimento econômico" (LENCIONI, 1999, p.193).

Ao tratar a ideia de espaço, é fundamental entender que seu conceito transcende o entendimento, apenas natural, sendo resultado, também, de construções culturais, uma vez que os processos diários de convivência e identidade, construídos na experiência de vida das pessoas, "ficam enraizados em lugares, em sua cultura, em sua história" (CASTELLS, 1999, p.440).

Para Corrêa (2001, p.292), a natureza e o espaço, socialmente produzido, constituem o ambiente geográfico, resultado de percepções, que surgem de variadas bases culturais, expressas pelos variados grupos sociais. Ao relacionar-se tal ambiente com a atividade turística, é possível identificar que, as pessoas são conduzidas a optarem por um espaço, ou melhor, por uma porção do espaço geográfico, identificado como lugar. E será o lugar, transformado em espaço turístico, que será consumido pelo turismo, como 
resposta a diferentes fatores, já que "a ausência de todos os lugares num certo lugar que desperta, fascina e atrai" (CASTROGIOVANNI, 2003, p.45).

O espaço turístico está então, associado ao produto da relação antrópica com determinada paisagem e, sua utilização social e cultural do ambiente, que poderá influenciar um determinado processo de desenvolvimento para a produção do espaço, incluindo a produção do espaço turístico. Assim, a visão particular de organização, da atividade turística, pode definir a configuração e, a delimitação espacial.

O espaço assume, então, significado especial, quando se apresenta como "lugar de animação", de trocas de bens e de símbolos, de difusão de ideias, remetendo ao entendimento da necessidade constante de interações sociais que podem "favorecer processos de crescimento e mudança" (ALBAGLI; MACIEL, 2003, p.423).

O turismo pode ser caracterizado como atividade de consumo do espaço, e é por esse "consumo dos espaços pelo turismo que se gestam os territórios turísticos" (CRUZ, 2002, p.17). Dessa forma, o território do turismo representa uma fração funcional do espaço que, apropriado por diferentes atores sociais e constituído pela identidade de sua comunidade, passa a ser visto como resultante de um processo de turistificação do lugar, resultado da "convergência de diferentes fatores (sociais, econômicos, culturais) e não, simplesmente, de seus atributos naturais" (CRUZ, 2002, p.19).

Assim como os conceitos de espaço, lugar e território, o conceito de região é tema importante da geografia (tradicional, quantitativa, crítica e humanista). Com base na abordagem de gêneros de vida do autor francês Vidal de La Blache (1845-1918), na geografia tradicional, região é espaço diferenciado e segmentado. Enquanto a geografia crítica mantém as classificações de região homogênea e região funcional da geografia quantitativa agregando-Ihe sentido social, a geografia humanista fundamenta o conceito na identidade e no sentimento de pertencimento da comunidade local (GOMES, 1995). 
Em ciência econômica, as regiões seriam áreas de mercado definidas por fronteiras econômicas. O conceito mais útil de região, em muitos casos, é o que se poderia chamar de região de desenvolvimento econômico, de onde sobressai a adoção de medidas, programas e intervenções para levá-la do nível em que se encontra economicamente hoje até alguns objetivos econômicos predeterminados (ABLAS e CZAMANSKI, 1982).

Boudeville (1973) faz uma distinção entre região homogênea, região polarizada e região de planejamento. A região homogênea caracteriza-se por um conjunto de partes semelhantes entre si, podendo predominar aspectos econômicos (renda per capita, poder aquisitivo), geográficos ou climáticos.

O conceito mais útil de região, em muitos casos, é o que se poderia chamar de região de desenvolvimento econômico, de onde sobressai a adoção de medidas, programas e intervenções para levá-la do nível em que se encontra economicamente hoje até alguns objetivos econômicos prédeterminados. Para Clemente e Higachi (2002, p.14), "a referência espacial das decisões econômicas, tanto do setor privado quanto do setor público, constitui uma região de planejamento".

Para Oliveira (2006, p.84), "no plano teórico, pode-se considerar que a região é decorrente da manifestação concreta da consciência regional percebida entre seus membros, possibilitando diferenciação entre quem está dentro (membros) e quem está fora (não membros). Em outros termos, podemos raciocinar que regiões não são fatos geográficos, mas fenômenos politicamente construídos".

Visualizando o território como algo relativo, podem-se identificar espaços de rapidez, que oferecem maior possibilidade de relações. São espaços de mandar, que servirão como ordenadores "da produção, do movimento e do pensamento, em relação ao território como um todo" (SANTOS e SILVEIRA, 2001, p.263). Esses espaços identificam-se com a noção de centralidade na organização regional, podendo influenciar, na determinação dos processos turísticos regionais. 
A ideia de densidade humana, como um dos indicadores do entendimento de centralidade, está relacionada às áreas onde ocorrem as trocas sociais, com maior intensidade, e que, "revelam e escondem, ao mesmo tempo, uma situação e uma história" (SANTOS e SILVEIRA, 2001, p.260). Percebe-se, assim, a cidade central, como a grande área de mercado, constituída pelas novas relações capitalistas, que modificam o território do trabalho.

A importância do centro é melhor representada, quando se entende seu papel de incentivador do mecanismo de mercado, criando possibilidades de expansão de renda e de geração de oportunidades econômicas. As cidades passam a ser vistas como entreposto, "como depositárias e como produtoras de bens e serviços" exigidos e consumidos por ela e pelo entorno (SANTOS; SILVEIRA, 2001, p.280). Pode, muitas vezes, exercer papel fundamental na região onde se processam suas relações próximas, organizando-se para atender tais demandas e servindo como verdadeiros fóruns regionais de debates.

Tais cidades seriam referências do projeto Destinos Indutores do Desenvolvimento Turístico Regional, do Ministério do Turismo do Brasil, pelo qual se selecionaram municípios que apresentavam um estágio de desenvolvimento turístico com padrão de qualidade internacional. $O$ turismo desses municípios seria influenciado pelo mesmo mecanismo de centralidade, que lhe confere a possibilidade de maior competitividade no mercado. $O$ território turístico recebe, assim, influências de cidades, que exercem poder de centralidade sobre o entorno.

Os centros regionais são constituídos pelas grandes e médias cidades, que reforçam as metrópoles, mas intensificam o processo de desmetropolização, difundindo regionalmente as atividades econômicas. Propõem-se novas formas de cooperação, e o que Santos (2005, p.291) identifica como "território corporativo", que possibilita redução de conflito e de exclusão social, numa troca proporcionada pela "complementaridade entre redes internas e externas" (ALBAGLI e MACIEL, 2003, p.423). 
A ideia de região surgiu da necessidade de intervenção em uma determinada unidade espacial, e é importante entender que "dificilmente, encontram-se regiões totalmente homogêneas" (FEGER et al., 2008, p.8). Retoma-se o questionamento da concepção de região turística, já que envolve municípios com diferentes níveis de preparação e de potencialidades, o que pode explicar a fragmentação cada vez maior dos conceitos de regionalização turística.

O Estado aparece como responsável pelo planejamento e pela coordenação central desse processo. O turismo é um dos mais expressivos setores da economia e surge como uma das alternativas decorrentes das estratégias do desenvolvimento regional, com ênfase nas teorias do desenvolvimento local. A ideia de regionalização do turismo é entendida como uma decisão, que possibilita incrementar o poder atrativo dos destinos turísticos, visando a maior integração entre os municípios, para formatar um produto turístico regionalizado. (DREHER e SALINI, 2008, p.5).

Para que esse processo seja adequado, é fundamental que a articulação e a integração entre os municípios sejam efetivas, isto é, as comunidades devem reconhecer seus municípios como pertencentes a uma região, perceberem-se como participantes de um processo turístico regionalizado e como parceiras na promoção. Para Lencioni (1999), região pode ser entendida em seu sentido afetivo, com base no sentimento de pertencer a um determinado lugar. Entre as vantagens do planejamento integrado de uma região turística, está a possibilidade de desenvolver um número maior de atrativos do que seria oferecido por um dos municípios isoladamente.

A regionalização deve valorizar os espaços locais, por meio da organização das identidades regionais e da promoção da diferenciação diante de outros lugares, pela atuação do poder público. O espaço local, percebido como destino turístico, é entendido como resultado da relação antrópica diante de determinada paisagem e é identificado pelo olhar do turista.

Uma região turística deve ser percebida por suas comunidades como espaço das próprias experiências na relação da cultura local com o território e 
com a paisagem. Caso contrário, servirá apenas para planejamentos políticos e administrativos exógenos, com pouco envolvimento local, dificultando o processo de desenvolvimento turístico endógeno.

\section{A Regionalização do Turismo no Brasil}

No Brasil, o Ministério do Turismo criou o Programa de Regionalização do Turismo, implantado no ano de 2003, demarcando o território nacional em regiões turísticas, visando a "descentralizar o turismo no país para maximizar a exploração adequada dessa atividade em cada região" (ARAUJO; CÂNDIDO; SILVA, 2009, p.2). É uma das premissas do Plano Nacional de Turismo.

De acordo com o Programa de Regionalização do Turismo, "a oferta turística regional adquire maior significância e identidade pela qualidade e pela originalidade capaz de agregar valor ao produto turístico" (BRASIL, 2005). Tal concepção enfatiza que é primordial a negociação com os atores locais para avançar no conceito tradicional de organização regional setorizada e perceber a importância de estabelecimento dos vínculos de confiança e de parceria no ordenamento da atividade turística.

A proposta visava a impulsionar o desenvolvimento turístico, como fator de desenvolvimento endógeno, de forma regionalizada e não mais baseada no município, como no Programa Nacional de Municipalização do Turismo (PNMT), criado em 1994. Produziu-se um Mapa de Regionalização, no ano de 2004, com 219 regiões turísticas no território brasileiro, que, mais tarde, foi condensado em 200 regiões e, posteriormente, em 111 regiões turísticas, quatro localizadas no Rio Grande do Sul, também identificadas como Zonas Turísticas - Serra, Missões, Litoral Norte e Porto Alegre-Metropolitana.

No ano de 2005 surgiu a ideia das governanças locais, posteriormente definidas como uma "organização representativa dos poderes público, do setor privado, do terceiro setor e da sociedade civil organizada dos municípios integrantes da Região Turística" (BRASIL, 2007, p.16). 
Como finalidades do Programa de Regionalização do Turismo têm-se:

Promover o diálogo, a discussão e a tomada de decisão participativa entre os atores envolvidos com o desenvolvimento do turismo regional; fazer a gestão do processo de construção e implementação do Plano Estratégico de Desenvolvimento do Turismo Regional; promover articulações e integração dos atores locais/regionais, controlar e monitorar as ações; zelar para que o desenvolvimento do turismo na região se faça sob a égide dos princípios do Programa: a descentralização, a integração, a participação e a sustentabilidade ambiental, sócio-cultural e econômica (BRASIL, 2007).

Uma das questões a serem definidas é o comprometimento dos atores da organização regional com o desenvolvimento endógeno, baseado na busca de recursos locais, ou se o interesse, parte, apenas, das possibilidades de captação de recursos externos oriundos de programas governamentais, que incentivam e priorizam o desenvolvimento turístico regionalizado. Em alguns casos, os próprios atores do turismo não têm entendimento claro da atividade, e da importância de uma organização regionalizada do turismo. Em outros momentos, suas escolhas e determinações são intuitivas, ou baseadas em fatores como políticas regionais administrativas, mas que, em alguns casos, são alheias ao turismo.

\section{A Regionalização do Turismo no Rio Grande do Sul e a Criação das Zonas Turísticas (1976 a 1982)}

De acordo com Flores (1993, p.14), a criação do primeiro órgão oficial de turismo do Rio Grande do Sul data do ano de 1950. Oficializou-se, pela gestão pública, o turismo no estado com o Conselho Estadual de Turismo e o Serviço Estadual de Turismo, cujo funcionamento foi adiado por falta de recursos. No ano de 1959, o estado tornou-se pioneiro na criação de um órgão oficial de fomento ao turismo, provendo "recursos adequados para sua instalação e funcionamento" (FLORES, 1993, p. 14).

Em 1971, foi criada a Secretaria de Turismo do Rio Grande do Sul. A leitura turística do território havia sido uma iniciativa do Touring Clube do 
Brasil, no ano de 1940, quando se criou o primeiro inventário turístico de que se tem notícia no estado, um cadastro de atrações naturais, hotelaria, transportes e serviços (FLORES, 1993).

O documento mais antigo que aborda a regionalização é o Plano Estadual de Turismo, do ano de 1976. O documento dividiu o estado em zonas turísticas. Importante lembrar o conceito de zona, adotado por Boullón (2002), como a maior unidade de análise e estruturação do universo espacial turístico. A superfície de cada zona é variável, sendo delimitada pela forma de distribuição dos atrativos turísticos.

Dentro de cada zona turística foram identificados pólos turísticos, nomeados como subzonas, que receberiam ações prioritárias, por meio de programas específicos. Tal entendimento parece refletir a ideia de centralidade nos processos de organização regional. Para a identificação das referidas zonas, foram definidos critérios como: aspectos geo-topográficos, étnicoculturais e econômicos. O território do Rio Grande do Sul foi, então, organizado em sete zonas turísticas ${ }^{3}$.

Quanto aos pólos turísticos (subzonas), foram identificados variados municípios, definindo, como critérios, a existência de: recursos turísticos significativos (naturais, históricos, artísticos ou culturais); infraestrutura básica (acesso, urbanização); equipamentos turísticos (superestrutura, indústria complementar ou suplementar); e correntes turísticas significativas (internas e externas). Para cada pólo, o documento indica como área polarizada, ou seja, sob sua influência, todas as áreas contíguas aos municípios elencados, reforçando a ideia de influência do centro em seu entorno.

\footnotetext{
3 Zona do Litoral (Subzonas Costa do Sol e Zona Sul); Zona da Serra (Subzonas Uva e Vinho, Campos de Cima da Serra e Hortênsias); Zona da Grande Porto Alegre (Subzonas Vale do Rio Pardo e Vale do Alto Taquari); Zona do Alto Uruguai (Subzonas Estâncias Hidrominerais e Produção); Zona das Missões; Zona do Centro (Subzonas Vale do Jaguari e Vale do Jacuí) e Zona da Fronteira (Sub-zonas Campanha e Fronteira Oeste).
} 
ISSN: $1982-6125$

\section{Centros Turísticos Efetivos e Potenciais do Rio Grande do Sul (1983 a} 1986)

O governo do estado elaborou um documento intitulado Turismo: Estratégia de Ação - 1983/1985, que previa "orientar o Poder Público Municipal quanto à sua função específica de turismo racionalmente delimitada: regional, estadual, nacional e/ou internacional" (RIO GRANDE DO SUL, 1983).

A organização regional da produção do turismo estava fundamentada em critérios de zonas efetivas, com interesse em nível nacional, indicação no zoneamento turístico da EMBRATUR e existência de valores significativos e evidentes de ordem natural e cultural, e zonas potenciais, com interesse regional, existência de patrimônio natural e cultural, existência de condições de acesso e localização favorável para integração em roteiros comerciais.

O zoneamento identificou nove zonas turísticas, divididas em centros turísticos efetivos e potenciais, identificados por municípios que substituíram a noção do pólo, ou subzona do plano anterior, assim definidas: Zona da Serra; Zona da Grande Porto Alegre; Zona do Litoral Norte; Zona das Missões; Zona das Hidrominerais; Zona da Campanha; Zona dos Vales; Zona Central e Zona Sul.

A Secretaria de Turismo foi extinta no ano de 1984, e a gestão do turismo foi transferida para a Secretaria da Indústria e Comércio. No mês de janeiro do ano de 1985, foi lançado o documento Turismo RS - Ações Básicas de Desenvolvimento, que identifica a graduação dos pólos turísticos em seus distintos estágios de desenvolvimento.

Em outubro de 1985, os pólos foram identificados como: turisticamente desenvolvidos; em vias de desenvolvimento, ou potencialmente viáveis para o desenvolvimento turístico. Enfatizavam-se os municípios geradores de fluxo externo do estado e sua integração regional, a fim de realizar programas de investimentos e orientar a comercialização turística adequada a cada respectiva realidade local e regional. Como resultados do documento, foram criadas comissões com funções específicas para cada programa. A ideia de 
centralidade é mantida, propondo-se investimentos e orientação diferenciada, para regiões em diferentes processos de desenvolvimento turístico.

No ano de 1986, foi lançado, pela Secretaria da Indústria e Comércio, o documento Subsídios para a Regionalização Turística do Estado, resultado de trabalho desenvolvido pela Comissão de Regionalização Turística, instalada em 1985, e que visava à realização de estudo de critérios, funções e institucionalização das regiões e pólos turísticos.

A comissão definiu que "região deve ser considerada como uma conjugação entre espaço e sociedade, ou seja, o conjunto formado por um espaço natural original, por transformações imprimidas a esse espaço por grupos sociais e por manifestações da cultura desses grupos" (RIO GRANDE DO SUL, 1986). Identificava-se a necessidade de outros estudos para definir o processo de regionalização turística, com base em subsídios como paisagens naturais, história cultural e economia. É importante questionar se tal proposta foi analisada e desenvolvida na organização regional do turismo nos anos seguintes.

\section{Programas dos COREDES (1991 a 1994), Recriação da Secretaria (1995 a 2003) e Modelo para o Ministério do Turismo (2003 a 2004)}

Em 1991, a gestão pública do turismo, do Estado do Rio Grande do Sul, continuava vinculada às políticas determinadas pela Secretaria de Indústria e Comércio. A política para o setor foi sistematizada no Plano de Desenvolvimento da Indústria do Turismo, organizado em quatro programas: ampliação da demanda turística; organização e desenvolvimento da oferta turística; manutenção da qualidade da matéria-prima; e regionalização turística.

Para entender o processo de regionalização, do governo do estado, durante esse período, é fundamental o conhecimento da organização regional, proposta na formatação dos Conselhos Regionais de Desenvolvimento (COREDES), implantados em parceria com a Federação das Associações de 
Municípios do Rio Grande do Sul - FAMURS, que serviram de base para a organização espacial do turismo.

As vinte e duas regiões foram agrupadas por características e identidades locais, considerando as potencialidades comuns de desenvolvimento. As regiões turísticas passaram a corresponder aos mesmos critérios de organização dos COREDES, assim distribuídas: Vale do Rio dos Sinos, Metropolitana Delta do Jacuí, Litoral Norte, Hortênsias, Serra, Paranhana - Encosta da Serra, Nordeste, Médio Alto Uruguai, Norte, Produção, Noroeste Colonial, Fronteira Noroeste, Missões, Campanha, Fronteira Oeste, Central, Alto Jacuí, Vale do Caí, Vale do Rio Pardo, Vale do Taquari, Centro Sul e Sul.

Tal organização regional do turismo parece refletir a ideia de organização político-administrativa, instituída pelo governo do estado, que visava o desenvolvimento econômico regionalizado, não considerando aspectos importantes, para o estabelecimento de relações produtivas no turismo.

As nove zonas turísticas foram mantidas, sendo identificadas, ou pelo atrativo, ou pelo produto, ou pela marca para atração e para incremento de fluxo turístico. Os municípios foram identificados como: turisticamente desenvolvidos; em vias de desenvolvimento e potencialmente viáveis para o desenvolvimento turístico, entendendo-se que o setor constitui-se pelos fatores determinantes das identidades culturais, físicas e econômicas dos municípios, refletidas de forma espontânea, no processo de regionalização. Cabe questionar o quanto a regionalização, baseada nos Coredes, considerou tais fatores, ou se baseou nas relações econômicas tradicionais.

No período de 1995 a 2003, manteve-se o mesmo modelo de regionalização, quando o programa de ações da SETUR-RS, instituiu um novo modelo, organizado em 24 microrregiões, incluindo Campos de Cima da Serra e Rota das Terras, desmembradas, por solicitação das governanças locais do turismo, totalizando as mesmas nove zonas turísticas. A organização regional do turismo, enquanto política pública atendia, assim, à solicitação das 
comunidades, representadas pela instância de governança legalmente instituída.

O novo processo de organização regional, proposto em 05 de junho de 2000, resulta de ações de planejamento, instituídas a partir da implantação do Fórum Estadual de Turismo e dos 24 Fóruns Microrregionais, em conjunto com entidades do setor, universidades, representantes do Sistema " $S$ ", órgãos públicos, privados e não governamentais, em busca de ações integradoras e de uma linguagem comum (RIO GRANDE DO SUL, 2000).

O Fórum Estadual de Turismo, coordenado pela SETUR-RS, passou a ter reuniões periódicas assistidas pelos representantes das microrregiões, indicados para a função de interlocutores dos anseios regionais, cumprindo papel importante no reconhecimento das regiões. A regionalização configurava-se ainda em nove zonas e 24 regiões.

Em 2003, parte da equipe de trabalho da SETUR-RS, foi integrada ao recém criado Ministério do Turismo - MinTur. Significativa parte dos programas desenvolvidos no Rio Grande do Sul, passa a ser referência para projetos do MinTur, como a proposta de regionalização do turismo. O Fórum de Turismo tornou-se modelo nacional, com a criação de Fóruns Estaduais em todas as unidades federativas.

\section{Atualização do Mapeamento e Mudança de Zonas para Regiões Turísticas (2005 a 2009)}

No mês de abril de 2004, realizaram-se no Rio Grande do Sul três Oficinas de Planejamento do Programa de Regionalização do Turismo, com o objetivo de definir a estratégia de implantação do programa Roteiros do Brasil. Na primeira, participaram os representantes das regiões turísticas, quando se discutiu o nome ou marca com que cada região se identificava, bem como se redefiniram os parceiros locais. Na segunda, participou a equipe técnica da SETUR-RS, e na terceira, participaram os parceiros estratégicos do estado Sebrae, Senac e instituições de ensino superior. 
O estado adotou os conceitos de região e microrregião, abolindo a ideia de zonas turísticas. Tal questão parece indicar a ideia de planejamento centrado em unidades regionais menores e, possivelmente, com identidades mais próximas.

No mês de setembro de 2005, realizou-se uma Oficina de Atualização do Mapeamento das Regiões Turísticas do Estado do Rio Grande do Sul, sendo convidados representantes das 24 microrregiões, que exerceram o direito de optar pela denominação que julgassem mais interessante para a organização local dos destinos turísticos ${ }^{4}$.

No mês de junho de 2006, realizou-se, em São Paulo, o workshop de Planejamento Estratégico, focado nas Agências Macrorregionais de Desenvolvimento Turístico com os seguintes objetivos: 1) consolidar a macroregião como um destino turístico competitivo; 2) gerar e potencializar negócios e produtos no âmbito da integração macro-regional e das atividades do turismo; 3) possibilitar a formação de uma ampla rede de relacionamento institucional e empresarial, composta simultaneamente por várias instâncias estaduais e distintos setores da atividade turística; 4) agilizar a difusão e dinâmica do processo do desenvolvimento do turismo na macro-região; 5) captar recursos em projetos de desenvolvimento do turismo macro-regional; 6) fortalecimento institucional das entidades que compõem a Agência e os Fóruns/Conselhos Estaduais de Turismo e Interagir e; 6) articular com as comissões de turismo do Senado e da Câmara e com os parlamentares estaduais e federais para uma melhor execução dos recursos das emendas individuais, de comissão e de bancada.

No ano de 2007, as zonas turísticas passaram a ser denominadas de regiões turísticas, e surgiu a décima região intitulada Yucumã, desmembrada da Zona das Missões, por solicitação da governança local. Esse exemplo identifica a falta de sentimento de pertencimento, que existia na região, uma

4 Vale do Rio dos Sinos, Porto Alegre e Delta do Jacuí, Litoral Norte Gaúcho, Campos de Cima da Serra, Hortênsias, Uva e Vinho, Vale do Paranhana, Rota das Araucárias, Águas e Pedras Preciosas, Termas e Lagos, Cultura e Tradição, Rota do Yucumã, Rota do Rio Uruguai, Missões, Campanha, Fronteira Gaúcha, Central, Rota das Terras, Jacuí Centro, Vale do Caí, Vale do Rio Pardo, Vale do Taquari, Centro Sul e Sul. 
vez que o atrativo principal, para criar a unicidade, era o Salto do Yucumã, uma queda d'água no Rio Uruguai. Independentemente da existência desse potencial turístico, os municípios que formariam a Região Yucumã, eram divulgados no mercado como integrantes da Zona das Missões, mesmo sem qualquer identificação com o passado missioneiro do estado. O Rio Grande do Sul estruturava-se em 24 microrregiões $^{5}$.

No ano de 2009, surgiu a $11^{\text {a }}$ região, intitulada Rota das Terras, que se desmembrou da Região Central, também por solicitação da governança local. Posteriormente, ainda no ano de 2009, com a retirada do programa de regionalização da micro-região Jacuí-Centro, o estado passou a ter onze regiões e 23 microrregiões. Tal formatação permanece até o ano de 2010. Cabe questionar quais fatores permanecem influindo na identificação das regiões ou microrregiões, uma vez que tais critérios não parecem claros.

\section{Síntese Analítica do Processo de Regionalização do Turismo do Rio Grande do Sul}

Os processos iniciais de organização do turismo no Rio Grande do Sul adotaram, como unidade, o município e suas potencialidades, para definir as estratégias de ação. A proposta de regionalização fundamentava-se em investimento, promoção e comercialização diferenciados. Os programas de regionalização turística iniciaram em 1976, quando o estado foi dividido em sete Zonas Turísticas, obedecendo a aspectos geo-topográficos, étnicoculturais e econômicos. As zonas foram divididas em subzonas, que correspondiam aos pólos turísticos e que receberiam investimentos especiais do governo.

\footnotetext{
5 Vale do Rio dos Sinos, Porto Alegre e Delta do Jacuí, Litoral Norte Gaúcho, Rota das Araucárias, Hortênsias, Vale do Paranhana, Uva e Vinho, Campos de Cima da Serra, Termas e Lagos, Cultura e Tradição, Águas e Pedras Preciosas, Rota do Yucumã, Rota do Rio Uruguai, Missões, Central, Vale do Caí, Vale do Taquari, Vale do Rio Pardo, Campanha, Fronteira Gaúcha, Centro Sul, Sul, Rota das Terras.
} 
Na regionalização do turismo no estado do Rio Grande do Sul, identificam-se seis fases: 1) criação das zonas turísticas (1976); 2) zoneamento em centros turísticos efetivos e potenciais (1983 a 1990); 3) programas de turismo no contexto da criação dos COREDES (1991 a 1994); 4) extinção da Companhia Riograndense de Turismo e recriação da Secretaria de Estado de Turismo (1995 a 2003); 5) os programas de turismo do Rio Grande do Sul como modelos para o Ministério do Turismo do Brasil (2003 a 2004); e 6) atualização do mapeamento e mudança de zonas para regiões turísticas (2005 a 2009).

Desde as primeiras etapas não houve, porém, entendimento da real importância da organização regional e dos critérios de institucionalização. As regiões eram definidas de acordo com as políticas públicas muitas vezes dissociadas da realidade do turismo e com a necessidade de apoio, de reconhecimento e de investimentos no setor. Os mecanismos utilizados na seleção e determinação dos territórios turísticos podem ser questionados, quanto ao poder de conquista de mercado.

A partir do ano de 1985, os pólos turísticos passaram a ser identificados de acordo com diferentes graduações de desenvolvimento turístico, justificando políticas específicas de investimentos. A regionalização foi critério de programas de financiamento e promoção, de acordo com o nível de organização turística. O documento Subsídios para a Regionalização Turística do Estado, lançado pela Secretaria da Indústria e Comércio, em 1986, foi relevante, pois expressava a decisão de não delimitar regiões turísticas, estabelecendo a caracterização das paisagens naturais, dos aspectos históricos, culturais sociais e econômicos do estado. Tal orientação, entretanto, não parece ter sido considerada nos planejamentos futuros.

No ano de 1991, as zonas turísticas foram definidas com base no arranjo desenvolvimentista dos COREDES, com objetivo de manter características mais identificadas com a atividade. Essa foi a mais clara proposta de aplicação de conceito de organização regional no estado do Rio Grande do Sul. O modelo de COREDES não foi, porém, suficiente para atender às necessidades turísticas, 
gerando discussões entre os atores municipais, que não se reconheciam como partícipes de uma região. Essas discussões mostram a relevância da participação da comunidade local, com base no conceito de governança do turismo regional e nos valores das identidades sociais e culturais.

Mesmo que sua vanguarda não represente liderança no desempenho no setor em relação às demais unidades da federação e que a regionalização não tenha se definido com a participação direta dos atores das comunidades locais, o Rio Grande do Sul é pioneiro no Brasil nas políticas de organização regional do turismo. A política de pólos turísticos, criada pelo governo do estado em 1976, readequada de acordo com a graduação, em 1985, foi aplicada, no ano de 2008, pelo Ministério do Turismo do Brasil, para os destinos indutores.

Tal entendimento identifica a ideia de centralidade e de influência sobre o entorno de alguns municípios com características turísticas diferenciadas. Apenas a partir das discussões promovidas pelo Ministério do Turismo, que possibilitaram aos atores envolvidos no processo definir sua região, é que houve maior comprometimento e valorização da regionalização turística do estado, em razão da maior participação dos atores das comunidades locais.

\section{Considerações Finais}

O objetivo deste artigo foi analisar os processos de regionalização turística do Rio Grande do Sul e as características e fatores da determinação dos espaços turísticos regionalizados do estado. Na fundamentação teórica, as questões do estudo abordaram os critérios da definição do espaço turístico, os conceitos e os programas políticos que fundamentam a ordenação territorial para o desenvolvimento do turismo.

A pesquisa proporcionou compilação e revisão dos diferentes estágios da regionalização turística do Estado do Rio Grande do Sul. Baseado em tal análise, é possível identificar a importância da presença de cidades, consideradas de grande atrativo turístico, como definidoras de processos de regionalização, agrupando municípios localizados em sua área de influência. 
Desde a proposta dos pólos turísticos, dos centros turísticos, até a implantação dos destinos indutores, tais cidades contam com apoio privilegiado dos programas de desenvolvimento turístico, seja do estado, seja do governo federal.

Outra análise necessária está relacionada, à importância da governança local, como fator de interlocução da região, com as políticas públicas do turismo. São os representantes de tais instâncias, os interlocutores adequados, para o reconhecimento das identidades locais e para a formulação de propostas que atendam os anseios de organização turística regionalizada.

Parece importante investigar o quanto os processos de regionalização do turismo, são percebidos e aprovados, pelos gestores e, pela comunidade envolvida. Propostas que possibilitem discussões das políticas de regionalização do turismo, poderiam contribuir para a formatação de regiões, representativas da visão local de identidade e, do produto turístico a ser formatado, cabendo aos gestores e comunidades, dos municípios turísticos, um importante papel na definição de seus reais, e potenciais, parceiros locais.

O presente estudo buscou auxiliar na discussão das políticas públicas de organização regional do turismo, que não se encerra com este trabalho e identifica a necessidade de critérios mais claros na organização dos produtos turísticos regionalizados.

\section{Referências}

ABLAS, Luiz \& CZAMANSKI, Stan. Agrupamentos e complexos industriais: uma revisão de métodos e resultados. In: LONGO e RIZZIERI. Economia urbana: localização e relações intersetoriais. São Paulo: IPE - USP, 1982.

ALBAGLI, Sarita; MACIEL, Maria Lucia. Pequena empresa: cooperação e desenvolvimento local. Rio de Janeiro: Relume Dumará: UFRJ, Instituto de Economia, 2003.

ARAUJO, Carolina; CÂNDIDO, Débora; SILVA, Mauro. Políticas de turismo: a percepção do empreendedor local em relação ao turismo no Vale do Café fluminense. Observatório de Inovação do Turismo - Revista Acadêmica. Fundação Getúlio Vargas - FGV. v. 4. n.1. Rio de Janeiro, 2009.

BENI, Mário Carlos. Turismo, interfaces, desafios e incertezas. Caxias do Sul: Educs, 2001. 
ISSN: $1982-6125$

BOUDEVILLE, Jacques, R. Os espaços econômicos. São Paulo: Difel, 1973. BOULLÓN, R. C. Planejamento do espaço turístico. Bauru: Edusc, 2002.

BRASIL. Ministério do Turismo. Programa de Regionalização do Turismo. Brasília, DF. 2005. Disponível em: <http://www.turismo.gov.br/turismo/programas acoes/regionalizacao turism o/>. Acesso em: 19 abr 2010.

- Ministério do Turismo. Institucionalização da Instância de Governança Regional. Módulo operacional 3. Secretaria Nacional de Políticas do Turismo. Brasília, DF. 2007.

CASTELLS, Manuel. A Sociedade em rede. In: A era da informação: economia, sociedade e cultura. v. 1. São Paulo: Paz e Terra, 1999.

CASTRO, Iná Elias de, et. al.. Geografia: conceitos e temas. Rio de Janeiro: Bertrand, 1995.

CASTROGIOVANNI, Antonio Carlos. Turismo na pós-modernidade (des)inquietações. GASTAL, Susana; CASTROGIOVANNI, Antonio Carlos (orgs.). Porto Alegre: EDIPUCRS, 2003.

CORREA, Roberto Lobato. Trajetórias geográficas. 2.ed. Rio de Janeiro: Bertrand Brasil, 2001.

CLEMENTE, Ademir e HIGACHI, Hermes Y. Economia e desenvolvimento regional. São Paulo: Atlas, 2000.

CRUZ, Rita de Cássia. Política de turismo e território. São Paulo: Contexto, 2002.

DREHER, Marialva; SALINI, Talita. Regionalização e políticas públicas no turismo: proposta bem (in)tencionada distante da práxis. In: Seminário de Pesquisa em Turismo do Mercosul. 5., 2008, Caxias do Sul. Anais... Caxias do Sul: UCS, 2008. 1 CD-ROM.

FEGER, José Elmar et al. Regionalização do turismo: uma análise espacial do Arranjo Produtivo Local Rota da Amizade. Observatório de Inovação do Turismo - Revista Acadêmica. FGV. v.3. n. 4. Rio de Janeiro, 2008.

FLORES, Hilda Agnes Hübner. Turismo no Rio Grande do Sul: 50 anos de pioneirismo no Brasil. Porto Alegre: Edipucrs, 1993.

GOMES, Paulo C. da Costa. O conceito de região e sua discussão. In: LENCIONI, Sandra. Região e geografia. São Paulo: Editora da Universidade de São Paulo, 1999.

OLIVEIRA, Henrique Altemani. Política internacional contemporânea: mundo em transformação. São Paulo: Saraiva, 2006.

RIO GRANDE DO SUL. Turismo: Estratégia de Ação - 1983/1985. Secretaria da Indústria e Comércio. Porto Alegre, 1983.

- Turismo - RS, ações básicas de desenvolvimento. Secretaria da Indústria e Comércio. Porto Alegre, 1985.

. SECRETARIA DE TURISMO, ESPORTE E LAZER. Instalação do Fórum Estadual de Turismo. Porto Alegre, Rio Grande do Sul, 2000.disponível em: <http://www.turismo.rs.gov.br/portal/index.php?q=secretaria\&cod =2\&id =11\& $\mathrm{fg}=2>$. Acesso em 23 jan. 2010.

Subsídios para a Regionalização Turística do Estado. Secretaria da Indústria e Comércio. Porto Alegre, 1986. 
MACHADO, Alvaro Luiz; TOMAZZONI, Edegar Luis. A regionalização turística do Rio Grande do Sul e sua contribuição como referência para a gestão regionalizada do turismo no Brasil. Revista Brasileira de Pesquisa em Turismo. v.5, n.2, p.226-247, ago. 2011.

ISSN: $1982-6125$

SANTOS, Milton; SILVEIRA, Maria Laura. O Brasil: território e sociedade no início do século XXI. Rio de Janeiro: Record, 2001.

SANTOS, Milton. Por uma outra globalização: do pensamento único à consciência universal. Rio de Janeiro: Record, 2005.

Artigo recebido em março de 2011.

Aprovado para publicação em julho de 2011. 